\title{
Capacities for irrigation water resource governance at the local level: a case study from the Upper East Region of Ghana
}

\author{
N. A. Nanedo ${ }^{1}$, J. C. Prior ${ }^{1}$, L. L. de Bruyn ${ }^{1} \&$ G. R. Marshall ${ }^{2}$ \\ ${ }^{1}$ Ecosystem Management, School of Environmental and Rural Sciences, \\ Faculty of Arts and Sciences, University of New England, Australia \\ ${ }^{2}$ Institute of Rural Futures, School of Behavioural, \\ Cognitive and Social Sciences, University of New England, Australia
}

\begin{abstract}
Local level institutional arrangements have been promoted by government and development agencies in Ghana as vehicles for sustainable water resource governance and rural development. However, these arrangements often lack the requisite capacities to fulfil their roles and responsibilities in this domain. This paper explores the existing capacities and capacity gaps among such institutional arrangements at regional, district and community level arrangements levels. Four case studies were undertaken of such governance in four communities of three districts in Ghana's Upper East Region involving in-depth and focus group interviews as well as field observations. We found that landholders' livelihoods have suffered as a result of the inadequate capacity within local level institutional arrangements to effectively manage irrigation water resources. The ineffectiveness of local level arrangements for irrigation water resource governance followed from irrigation governance responsibilities being devolved to local community organisations without adequate support for post project capacity building.
\end{abstract}

Keywords: Ghana, adaptive governance capacity, water resource governance.

\section{Introduction}

The role of local level organisations in addressing the challenges in common pool resources (CPR) for sustainable use has been widely acknowledged, encouraged and promoted by governments and development agencies as vehicles for sustainable common resources governance [1,2]. 
The early 1990s witnessed fundamental changes to the governance structures of public irrigation schemes in Ghana. The Tono and Vea medium-scale schemes in the Upper East Region, controlled by state irrigation company - Irrigation Company of Upper Region (ICOUR) - began measures to encourage farmer participation in its operations. Irrigators were facilitated to form farmer groups known as lateral groups that would represent the interest of the irrigators [3]. Similarly, beginning in 1992, the ownership and management of small scale irrigation schemes in the Upper East Region was rehabilitated under the International Fund for Agriculture Development (IFAD) and with funding from the Land Conservation and Smallholder Project (LACOSREP), which was transferred to the local communities. Water Users Associations (WUAs) were formed as local-level water governance structures to take up management responsibilities of the irrigation facilities. However, farmer-managed irrigation schemes were transferred to WUAs and the government-managed irrigation schemes in the Upper East of Region (UER) of Ghana are now faced with significant physical, social, financial and institutional governance problems $[4,5]$. The devolution of irrigation water resource governance, management roles and responsibilities to local communities can only be meaningful if the irrigation water user's associations have the requisite capacity to carry out the assigned functions. Irrigation water agencies at regional and district levels also need sufficient capacity to provide support to WUAs for effective local-level irrigation water governance.

This paper explores the existing capacities and capacity gaps for communitybased irrigation water governance in the UER of Ghana. In order to identify these gaps, a qualitative research method and a case study approach was used. Other methods that are used under the umbrella of the case study's method are focus groups, individual farmers and key informant interviews, field observations and secondary data from project reports (including evaluation reports), and farmers' bye-laws. One hundred and sixty one (161) individuals amongst four groups (District Assemblies decentralised departments, water user groups, government agencies at the regional level and traditional authorities including community leaders) were interviewed. Results from the interviews were collected based on purposive sampling to identify the relevant stakeholders in irrigation water governance at the local level. In order to explore the irrigation water governance capacities and capacity gaps, a semi-structured format was chosen for the interviews, which were then transcribed, coded and analysed using NVivo 9.2 software. The interviews were also kept anonymous. In line with the qualitative data analysis methods, the transcribed data was categorised through coding carried out by the researchers and the codes were grouped in order to answer the research questions.

Section 2 of this paper describes the study area and the research context whilst section 3 examines the available capacities and capacity gaps. Sub-section 3.1 assesses the existing capacities for irrigation water governance at the local level and sub-section 3.2 examines the capacities and performance of community-based irrigation water governance. Section 4 concludes the paper. 


\section{The study area and research context}

The case studies were collected from four villages namely, Durongo and Nyariga in Bolgatanga Municipality, Winkogo in Talensi District, and Vea in Bongo District respectively. The three districts fall within the Upper East Region of Ghana. The region falls under the semi-arid West African savannah zone, characterised by unpredictable environmental conditions and unreliable rainfall patterns. The region is one of the most vulnerable and poorest in Ghana.

The choice of the study area is based on the fact that water is scarce, irrigation development is critical to sustainable livelihood and government policies are promoting community-based irrigation water resource governance. Furthermore, the Upper East region has the highest concentration of irrigation facilities in Ghana. Additionally, the four villages were purposively selected to give a variety of approaches to irrigation water resources governance in the region. The selection is based on their particular differences in institutional arrangements, namely farmer-managed (i.e. Durongo and Winkogo) and government-managed (i.e. Vea and Nyariga) irrigation systems. The selected four villages have similar socio-cultural, economic and climatic characteristics. For the purpose of this study, small scale irrigation schemes are referred to as "farmer-managed" and large scale irrigation scheme as "government-managed". The "farmer-managed" schemes have small irrigation facilities located in one village while the government-managed irrigation scheme stretches across 8 villages.

\section{Available capacities and capacity gaps}

\subsection{Existing governance capacities for irrigation water governance at the local level}

The governance capacity, as used in this paper, refers to the capacities (abilities) to set and enforce rules, monitor and enforce compliance of rules, ensure accountability, plan, establish conflict resolution mechanisms, develop and maintain trust and legitimacy, provide effective leadership, mobilise community resources, communicate, and network with other stakeholders. The capacities identified are group into three categories: organisational, social and human capital. Organisational resources refer to the available funds and logistics at the regional, district and community levels. Human capital refers to the existing knowledge, abilities and skill sets available within the locality for irrigation water governance either at the regional, district or community levels. Social capital has been referred to as "connections among individuals - social networks and the norms and reciprocity and trustworthiness that arise from them" [6]. The social capital is considered in this paper as durable social networks, norms, trust, reciprocity (social support systems), sense of community and problem solving drives among the irrigators within the community. The socio-economic and biophysical contexts within which the irrigation water users operated had influenced the available 
capacities for irrigation water resource governance at the community level, which in turn influenced the performances of community level irrigation water governance.

\subsubsection{Human capital capacities for irrigation water governance}

The human capacities identified for irrigation water governance at the locality included: institutions and enforcement of institutions, leadership for leading and directing, community mobilisation, strategic planning, conflict resolution mechanisms and communication.

3.1.1.1 Institutional enforcement and compliance Institutions enforcement to control and monitor the behaviours of the water users was a major function of irrigation water governance in the study areas. Thus, the ability of WUA and lateral leaders to enforce and ensure compliance with these institutions was an important capacity for local level irrigation water governance. The presence of institutions and enforcement capacity is evident from the following interview responses:

The chief is the traditional political leader of the community and the rules and regulations made by him and his elders are respected and obeyed by the communities. So, once the chief endorses rules and regulations set by the WUA, then they have the support of the people (Interviewee: community leader, Durongo, DCL002. November 16, 2011. Source: interview results from study).

It was evident from the individual and focus group interviews with irrigators in all the communities that the village chiefs, WUA and lateral leaders had the legitimate authority to design institutions and enforce them. The leaders monitored and enforced the institutions through various forms of social sanctions such as fines, denial of access to land and water, warnings and so on. However, both focus groups and individual interviews with water users revealed that though efforts were made by the traditional authorities, WUA and lateral leaders to enforce the institutions, enforcement was not effective due to many factors. Factors accounting for the ineffectiveness of institutional enforcement and compliance included a lack of trust for the farmer leaders resulting from lack of financial accountability, low income resulting in poor yields and poor infrastructure to provide adequate water. Other factors included social inter-connectedness and the lack of monitoring capacities.

ICOUR, the main enforcement body in the government-managed schemes, did not have adequate organisational and human capacities (adequate staff, logistics, and financial resources) to monitor and enforce institutional compliance for irrigation water governance effectively. Similarly, irrigation agencies at the district and regional levels, which are responsible for the performance monitoring of community governance structures, lacked the requisite capacity (human and financial capabilities) to perform their functions in order to support effective community level irrigation water governance. Low crop yields due to pests and disease (parasitic nematodes infection), poor soil fertility and salinity, coupled 
with the high cost of farming inputs and low prices for irrigated crops (tomatoes in particular) translate into low farmer incomes and high transaction costs. This in turn, resulted in low financial capacity thereby affecting compliance with the institutions.

3.1.1.2 Leadership capacity Kim and Maubourgne [7] referred to leadership as the ability to inspire confidence and support among the people who are needed to achieve organisational goals. The majority of study participants in both individual interviews and in focus group discussion reported that the traditional authorities, WUA and lateral group leaders provided leadership capacities for collective actions around irrigation water resource governance, though not uniformly across all the case studies. Leaders helped design and enforce institutions and monitor water use among irrigators. Notwithstanding the important roles that both the formal (WUA and lateral) and informal (traditional authority) leaders played in local irrigation water governance, the majority of study participants indicated that local leadership in both government-and farmermanaged schemes was limited in mobilising irrigators for collective actions for effective water governance. For instance, in the farmer-managed schemes, the leaders rarely motivated and inspired confidence and support among the WUAs for collective action and self-governing initiatives.

"The success of a group depends on good leadership. We used to share ideas with other farmers in neighbouring communities in the past when our leaders were doing their work well, but the leaders we have now do not even call for meetings, so how then can they have knowledge of the problems at hand to organise vehicles for us to travel and interact with others?" (Interviewee: participant in Winkogo mixed FGD, WMFG1. January, 2, 2012. Source: results from study).

We don't trust them. You imagine that when your husband gives you money to go and buy ingredients to cook and you decided to take that money to pay for your water and land levy contributions and the man [the leader] who collects this money from you goes and spend it with his wife, how will you feel? It hurts a lot! Next time will you pay? (Interviewee: female, Winkogo, WFF052, December 27, 2011. Source: results from study).

This finding is consistent with the argument of other scholars [8] who stated that all other things being equal trust matters more to individuals when outcomes are unfavourable. Brockner et al. [8] explained further that the receipt of favourable outcomes does not raise issues of authorities' trustworthiness, as the outcomes themselves constitute evidence that the authorities can be counted on to perform behaviours desired by the trustee. In that case, trust is neither threatened nor critical in determining support for authorities. On the other hand, when outcomes are unfavourable, trust becomes more critical and authorities are unlikely to receive much support. 


\subsubsection{Community mobilisation capacities for irrigation water governance} Traditional authority structures and WUA leaderships played important roles in community mobilisation for irrigation water resource governance in both farmermanaged and government-managed schemes. The chiefs in the communities were relied upon for community mobilisation for irrigation water governance. However, distrust for WUA leadership in a case study community like Winkogo reduced the credibility and ability of the leaders to mobilise members to provide free labour and contribute money for scheme repairs and maintenance. The outcome of this was low internally mobilised resources for effective irrigation water governance. This meant that community mobilisation capacity for irrigation water resources governance was partly contingent on trust, transparency, legitimacy, and financial accountability of the service providers.

3.1.1.4 Conflict resolution capacities The conflict resolution capacity for irrigation water resources governance was available among the water user groups and the traditional authorities in the communities. The decentralised structures including existing traditional community social structures provided platforms for conflict mediation around water and land disputes. Formal structures such as the WUA leaders, ICOUR, officials from for instance department of agriculture, traditional authority systems, community elders, and peers were used to resolve conflicts. Irrigators acknowledged that their collective action rules, social structures and family ties offered better safeguards for resolving disrupting conflicts.

There are leaders in our individual farmer groups and a leader for all the farmer groups in the community called the chief farmer. Whenever there is any misunderstanding among the group members, the issues are referred to the group leader to solve. If these leaders cannot resolve them, it is referred to community leaders (chief and elders) for redress (Interviewee: female, Nyariga, NFF141. January 31, 2012. Source: results from study).

Interviews with the irrigators indicated that they had fewer conflicts regarding land allocation and water use in the communities because of the available conflict resolution capacities.

3.1.1.5 Planning capacity Planning involves defining organisational goals, establishing an overall strategy for achieving goals and developing comprehensive implementation strategies [9]. Planning can either be formal or informal. Informal planning does not usually contain written goals and objectives and is largely unshared with other organisations. Formal planning involves written goals, objectives and implementation strategies covering a certain time frame. Because these goals are documented, it is easy to share within and outside the organisation [9]. The term planning, as used in this paper, refers to both informal and formal planning since the study focuses on irrigation water resource plans at the district and community levels. However, planning as used at the community level refers to informal planning since the water users did not have the technical skills needed for formal planning. 
Interviews with irrigators in both farmer-managed and government-managed schemes reported that they set unwritten goals (best described as wishes) for their farming operations, were aware of the constraints and opportunities associated with irrigation water governance, and made efforts to minimise the constraints in order to take advantage of the opportunities. However, when asked to indicate whether they were aware of the existence of formal strategic plans for the WUAs, most of the irrigators were unaware of the existence of such formal plans. In addition, the WUA leaders in the farmer-managed schemes and ICOUR staff could not produce any strategic plan document when asked. This implies that WUAs and irrigation agencies rarely developed strategic plans to enhance irrigation water governance, but rather depended on intuitive reactions to the exigencies of the day. The farmers and community leaders had a shared vision regarding irrigation water governance, which they expressed in various ways, though this vision was not captured in any formal plans and therefore cannot be relied upon for effective decision-making. Interviews with all the regional district level stakeholder officials indicated that they had no strategic plans for irrigation water governance. Though the water users had informal plans, they were constrained with both financial and human resource capabilities to implement these plans.

\subsubsection{Organisational resource capacities for irrigation water governance}

Limited financial resources however reduced resource mobilisation capacities available for irrigation infrastructure repair and maintenance. The extent to which financial resource capacity constrained resource mobilisation was summarised in the following interview responses:

We don't have any other job apart from the irrigation farming. The difficulty is that most of us are jobless and what others also get from the irrigation farming is not sufficient to meet the contributions. In a nutshell there is poverty in the community which hinders any contribution or fund raising (Interviewees: women Focus Group, Durongo, DWFG, December 15, 2011. Source: results from study).

Funds mobilised from water users in the government-scheme through water and land levies were also inadequate for financing irrigation water resources governance. What the findings suggest is that an internally generated fund for local level irrigation water resource governance was limited.

\subsubsection{Social capital capacities}

Social capital capacities as referred to in this paper include durable social networks, norms, trust, reciprocity (social support systems), sense of community and problem solving drives among the irrigators within the community. These variables and how they contribute to local level irrigation water governance is discussed.

3.1.2.1 Sense of community Like in most agrarian rural communities in Ghana, responses from the irrigators revealed that they were socially inter-connected to one another due to extended pro-family relations derived through the same genealogical roots and ancestors. The social system of the villages had provided 
avenues for conflict resolution, community mobilisation and social support or reciprocity. The social inter-connectedness resulting in reciprocity was expressed in frequent responses by the majority of the participants as:

We had a traditional system of communal agricultural labour exchange supporting each other on rotational basis. This arrangement is based on community solidarity, cooperation and mutual support. This reciprocal social arrangement is still relevant to us in the management of the irrigation water resource (Interviewee: Community Leader, Durongo, DCL002. November 16, 2011. Source: results from study).

Bonding social capital available in the water user groups resulted in support and collaboration for collective actions required for irrigation water resource governance at the local level. Moser [10] argued that active reciprocal support networks within communities and participation in community activities facilitate trust and collaboration.

3.1.2.2 Problem solving drive Interviews with the majority of the water users and village leaders showed that they translated their sense of belonging into collective actions to solve problems relating to the irrigation water governance because of the benefits they derived from the irrigation facilities. Interview responses from some of the participants reflect their drive to solve their problems:

The responsibility of maintaining the dam solely lies in the community.

The time that part of the dam got broken, we ran helter-skelter looking for help from everywhere (Interviewees: mixed Focus Group, Winkogo, WMFG2. February 4, 2012. Source: results from study).

The sense of community as evident in the interviews responses provided internal drives to agree to form WUAs and lateral groups for irrigation water governance as suggested to them externally. The formation of the water user groups did not however necessarily provide adequate capacities to solve irrigation water resource governance problems in the case study villages. The WUAs and the lateral groups were not able to maintain irrigation canals. Nevertheless, the user groups constituted a capacity to be leveraged for irrigation water resource governance at the local level.

3.1.2.3 Trust-building Trust-building among the stakeholders was both vertical and horizontal. Vertical trust related to trust between the decentralised departments and agencies at the district level and the water user groups at the village level. Horizontal trust was trust between the WUA and lateral leaders and the irrigation groups at the village level. Interviews with the WUAs revealed that there was trust between the officials at the department of agriculture and the water users. At the community level, there was a relatively high level of trust placed in the WUA and lateral leaders. The irrigators trusted their leaders for decisions taken on behalf of the groups, feedback received when their leaders went to meetings on their behalf, commitment for irrigation improvement through voluntary services. The outcome of trust for the leaders' performance was collaboration for collective actions for irrigation water governance. There were however varying views from some of the irrigation participants which indicated a lack of trust for the WUA and 
lateral leaders. The lack of trust for the leaders related mainly to their lack of financial integrity and low performance in their roles and responsibilities. Lack of trust for the leaders undermined their abilities to motivate the water users to contribute towards irrigation infrastructure maintenance. Lack of trust for financial resource management negatively affected irrigation water resource governance capacity in both farmer-managed and government-managed schemes at the time of the study.

3.1.2.4 Social networks In this study the relevant social networks consist of social interactions among the irrigators within and outside their communities, and the district decentralised departments with the view of getting both financial and technical support to leverage available capacities for irrigation water resources governance. Responses from some of the irrigators signified that they had social networks within and outside their locality through which they received support. There were however, different views from some irrigators from both farmermanaged and government-managed schemes that they had limited networks outside their localities apart from MOFA and ICOUR in the case of governmentmanaged schemes.

We had that network with other farmers in other communities in the past due to effective leadership, but the leaders we have now do not even call for meetings, so how then can they have knowledge of the problems at hand to organise vehicles for us to travel and interact with others? (Interviewees: Mixed Focus Group, Winkogo, WMFG1, January 2, 2011. Source: results from study).

The irrigators did connect with other communities some time ago but were not able to maintain those social networks. Rather than being durable networks, they were intermittent opportunistic connections from which they obtained useful information, but it was not a continuous relationship they could benefit from. Thus, the irrigators who held the view that they had no social network did not consider a one-time visit to other irrigation communities as a viable network that could leverage the necessary capacities needed for irrigation water resources governance. The irrigators explained that the primary reasons why they had weak social networks were due to ineffective leadership and their low level of education.

\subsection{Governance capacities and performance of community-based irrigation water resource governance}

This section focuses on how the available capacities supported community-based irrigation water resources governance at the local level in terms of participation, ownership and control - Water Users Participation in Irrigation Water Governance at the Local Level.

Agrawal and Gibson [11] referred to participation as the collective action of communities to: (1) define priorities and develop rules regarding the use and the sharing of the resource, its management and its conservation; (2) implement and monitor the institutions developed; (3) enforce the institutions to ensure that the sanctions are applied; and (4) mediate and resolve conflicts that arise. All of these 
four indicators of participation existed to some extent among the irrigation water users. However, the extent to which these participation indicators manifested among the water users was largely influenced by the effectiveness of the leadership. The interview responses indicated that leadership capacities to some extent encouraged water users' participation in collective actions necessary for effective community-level irrigation water resource governance. These included financial and labour contributions towards infrastructure repair and maintenance, conflict resolution, information sharing (communication) at organised meetings, networking with external agencies, rules enforcement and compliance. Conversely, evidence from the interview responses from some of the water users in both farmer-managed and government-managed schemes revealed that the WUA and lateral leaders as well as ICOUR management were ineffective in organising the water users to participate in local level irrigation water governance effectively.

Leadership capacities were reduced due to lack of effective communication and lack of financial accountability, which resulted in a lack of trust for the leaders. The observed corruption among the ICOUR staff, lateral and WUA leaders in Winkogo, Vea, and Nyariga by the irrigators reduced trust for them and contributed to low participation as well as non-compliance with the institutions, and cooperation and therefore limited governance capacities for community-based irrigation water resource governance.

\subsubsection{Governance capacity and irrigation water facility ownership}

To avoid free riding and ensure accountability, rules were designed and enforced and rule violators were sanctioned. The WUA leaders and the traditional authorities to some extent were able to mobilise the water users for collective actions. The leaders designed and enforced rules and also sanctioned rule violators. Thus, ownership of irrigation water resources was supported through governance capacities of leadership, institutions, community mobilisation, and problem solving drives. Notwithstanding the transfer of ownership and management responsibilities to the communities in the farmer-managed schemes on one hand and to the communities and ICOUR in the case of the governmentmanaged schemes on the other hand, the irrigators still felt the government owned the water. Some of the irrigators stated:

As for the project it is for ICOUR. If we pay the water levy they will give us water and if we don't pay we don't get water (Interviewee: Lateral Leader, Nyariga, NFL107. November 27. Source: results of study).

It is government's responsibility to do repair and maintenance on the dam and not ours. We only make little contributions to do minor repairs which are within our limits (Interviewee: male, Durongo, DFM015. January 9, 2012. Source: results of study).

The water users' feeling towards irrigation infrastructure ownership in both farmer-managed and government-managed schemes was limited. The water users did not clearly understand the level of repair and maintenance that was their responsibility. This study argues that a lack of clear roles and responsibilities resulted partly from lack of effective planning capacities to identify specific roles 
and responsibilities and how to fulfil these roles and responsibilities. It was also partly due to a lack of effective communication on ownership, roles and responsibilities. Field observations revealed that all the canals were broken down and water could not be transported through them to the farms for productive irrigation activities for sustainable livelihoods.

\subsubsection{Governance capacities and irrigation water resource control}

Some scholars [12] have stated that communities must have control over their resources by electing their own leaders, make their own plans and design rules, mobilise their own resources for support, and build their own management and leadership skills. The analysis of interview responses from the water users, particularly from the farmer-managed schemes, demonstrates that the water users had some level of control over their irrigation water resources. In both farmermanaged and government-managed schemes, the water users elected their water management leadership to mobilise them for collective action to solve some of the irrigation water resources governance problems. The water users had also designed their own institutions regarding access to water and land, and sanctions for rule violation.

Control over irrigation water resources varies between the farmer-managed schemes and government-managed schemes. The water users in the governmentmanaged schemes had limited control over irrigation water resource governance. In spite of the efforts made by the water users to elect their own leaders, design rules, mobilise resources for support, and build management and leadership skills, ICOUR still had a greater control over the management of the irrigation scheme. The water user groups could not make any major decisions regarding canal water supply and schedules. ICOUR's tight control over almost all major management decisions suggested that meetings were just to inform rather than to discuss. Irrigators and traditional authorities still felt the dam was the property of the government being managed by ICOUR and they were subject to ICOUR's decisions. They did not have power to influence major decisions concerning the management of the dam. The inability of ICOUR to generate adequate resources to meet its full operational cost suggested that they had limited control over management of the government-managed schemes, hence depended on the government for support.

\section{Conclusion}

Research shows that there were limited governance capacities to support community-based irrigation water governance at the local level. The study found that inadequate leadership capacities constituted the main factor that impeded community-based irrigation water governance at the local level. Leadership capacities could be seen as the hub from which all other capacities for communitybased irrigation water resource governance derived their strengths. Decentralisation of irrigation water resources to the WUAs, lateral groups and ICOUR had not enhanced the capacity levels of these local level organisations for effective community-based irrigation water governance in both farmer-managed 
and government-managed schemes. Hence the impact of local level structures on governance outcomes of participation, ownership and control was low. The decentralised irrigation water resource governance in this form could be described as the government's efforts to hand over irrigation facilities to the water user groups at no cost but expect them to assume responsibilities, the cost of which they could not envisage or be prepared for. Thus, the caveat provided by Marshall [13] argues that any particular task should be devolved taking into account the capacity required to manage the issues involved effectively and that capacity is a prerequisite to community-based governance bodies and applies to the current case studies.

\section{References}

[1] Ostrom, E. (1992). Crafting Institutions for Self-Governing Irrigation Systems. San Francisco, California: ICS Press, pp. 113, 1992

[2] Tang, Y. S. Institutions and Collective Action: Self Governing in Irrigation. San Francisco, California: ICS Press, pp. 1-13, 1992

[3] Salifu, J. Personal communication, 26 January 2012, Senior Officer, Irrigation Company of Upper Region (ICOUR), Vea, Ghana

[4] Birner, R., McCarthy, N., Robertson, R., Waale, D. \& Shiffer, E. (2010) Increasing access to irrigation: Lessons learned from investing in small reservoirs in Ghana. Proc. of Ghana Strategy Support Program (GSSP)

[5] Namara, R. E., Horowitz, L., Nyamadi, B. \& Barry, B. (2011) Irrigation Development in Ghana: Past experiences, emerging opportunities, and future directions. Accra: International Food Policy Research Institute, pp. 1-43, 2011

[6] Putman, R. D. Bowling Alone: America's Declining Social Capital. Journal of Democracy, pp. 65-78, 1995

[7] Kim, W. C. \& Maubourgne, R. A. Parables of leadership. Harvard Business Review, 70(4), pp. 123-128, 1992

[8] Brockner, J., Siegel, P. A., Daly, J. P., Tyler, T. \& Martin, C. When trust matters: The moderating effect of outcome favorability. Administrative Science Quarterly, pp. 558-583, 1997

[9] Robbins, S. P., Bergman, R., Stagg, I. \& Coulter, M. (2003). Foundations of management. French Forest: Prentice Hall, pp. 198-200, 2003

[10] Moser, C. O. The asset vulnerability framework: reassessing urban poverty reduction strategies. World Development, 26(1), pp. 1-19, 1998

[11] Agrawal, A. \& Gibson, C. C. Enchantment and disenchantment: the role of community in natural resource conservation. World Development, 27(4), pp. 629-649, 1999

[12] Johnson, C. Uncommon ground: the 'poverty of history' in common property discourse. Development and Change, 35(3), pp. 407-434, 2004

[13] Marshall, G. R. Nesting, subsidiarity and community-based environmental governance beyond the local level. International Journal of the Commons, 2(1), pp. 75-97, 2008 